\title{
NMR Study of Hydrogen Exchange in the DNA Decamer Duplexes Containing the -10 galP1 Promoter Sequence
}

\author{
Kwang-Ho Choi, Eun-Hae Lee, Hee-Eun Kim, Yeon-Mi Lee, Ae-Ree Lee, Jin-Wan Park, \\ Myong Yong Choi, , and Joon-Hwa Lee* \\ Department of Chemistry and Research Institute of Natural Science, Gyeongsang National University, \\ Jinju, Gyeongnam 660-701, Korea.*E-mail: joonhwa@gnu.ac.kr andmychoi@gnu.ac.kr \\ Received February 24, 2011, Accepted March 23, 2011
}

Key Words : NMR, Hydrogen exchange, galP1 promoter, Transcription

Most Escherichia coli promoters are consists of two 6-bp sequence elements which are centered at $\sim 10$ and 35 nucleotides upstream of the transcription initiation point. ${ }^{1}$ The conserved region 4.2 and 2.4 of the RNA polymerase $\sigma^{70}$ subunit recognize -10 and -35 promoter elements, respectively. ${ }^{2}$ The open complex between $\sigma^{70}$ subunit and promoter elements, in which the promoter DNA is locally melted, is competent to initiate RNA synthesis according to the DNA sequence of template strand. ${ }^{3,4}$ Promoter opening is temperature-dependent; the most $-10 /-35$ promoter complexes display closed forms below $15^{\circ} \mathrm{C},{ }^{5}$ whereas promoter complexes on the extended -10 galP1 promoter remain open at $5{ }^{\circ} \mathrm{C} .{ }^{6,7}$ The reason for this unusual behavior of the -10 galP1 promoter is not completely understood.

The conserved A·T base pair at the -11 position of the promoters plays very important role in the initiation of E. coli transcription. ${ }^{8}$ The in vitro transcription with the -10 galP1 promoter was not initiated when this A base was substituted to other bases. ${ }^{8}$ To understand the function of the A-11 base in the transcription initiation process, the imino proton exchange rates were measured for the DNA decamer duplex containing the wild-type -10 galP1 promoter sequence (position: $-14 \sim-5$ ) (referred to as wt galP1, Fig. 1). The exchange rate constants of the imino protons for the wt galP1 duplex were compared with those of the modified galP1 promoters at the -11 position (see Fig. 1). This comparison indicates that some differences in the base pair dynamics are correlated with function of the -10 galP1 promoter during transcription initiation.

\section{Experimental Section}

All DNA oligonucleotides were purchased from M-biotech Co. (Seoul, Korea). The oligonucleotides were purified by reverse-phase HPLC and desalted by Sephadex G-25 column. DNA duplexes were prepared by dissolving two strands at a 1:1 stoichiometric ratio in an NMR buffer $(90 \%$ $\mathrm{H}_{2} \mathrm{O} / 10 \% \mathrm{D}_{2} \mathrm{O}$ solution containing $10 \mathrm{mM}$ sodium phosphate (pH 8.0) and $100 \mathrm{mM} \mathrm{NaCl}$ ). NMR experiments were carried out on a Varian Inova $600-\mathrm{MHz}$ spectrophotometer (KAIST, Daejeon) equipped with $x, y, z$-axis pulsed-field

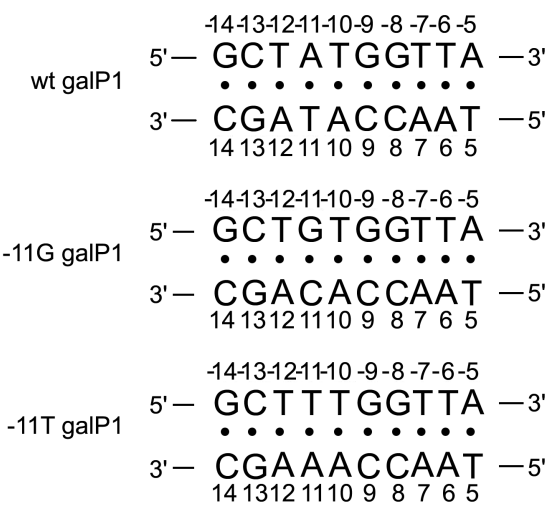

Figure 1. DNA sequence contexts of the wt, $-11 \mathrm{G}$, and $-11 \mathrm{~T}$ galP1 DNA decamer duplexes.

Table 1. Chemical shifts of proton resonances in the wt galP1 DNA decamer duplex

\begin{tabular}{|c|c|c|c|c|c|c|c|c|c|c|c|}
\hline Residue & Imino/Amino & $\mathrm{H} 2 / \mathrm{H} 5 / \mathrm{Me}$ & $\mathrm{H} 6 / \mathrm{H} 8$ & $\mathrm{H} 1^{\prime}$ & $\mathrm{H} 2^{\prime} / \mathrm{H} 2^{\prime \prime}$ & Residue & Imino/Amino & $\mathrm{H} 2 / \mathrm{H} 5 / \mathrm{Me}$ & $\mathrm{H} 6 / \mathrm{H} 8$ & $\mathrm{H} 1^{\prime}$ & $\mathrm{H} 2^{\prime} / \mathrm{H} 2^{\prime \prime}$ \\
\hline G-14 & 12.98 & - & 7.98 & 5.99 & $2.69 / 2.76$ & T5 & n.d. ${ }^{a}$ & 1.64 & 7.31 & 5.70 & $1.64 / 2.12$ \\
\hline $\mathrm{C}-13$ & $6.68 / 8.32$ & 5.35 & 7.52 & 6.06 & $2.16 / 2.55$ & A6 & - & 7.44 & 8.32 & 5.87 & $2.85 / 2.91$ \\
\hline $\mathrm{T}-12$ & 13.66 & 1.67 & 7.44 & 5.72 & $2.23 / 2.54$ & A7 & - & 7.80 & 8.17 & 6.15 & $2.66 / 2.84$ \\
\hline A-11 & - & 7.32 & 8.37 & 6.26 & $2.67 / 2.93$ & $\mathrm{C} 8$ & $6.43 / 7.94$ & 5.17 & 7.23 & 5.80 & $2.00 / 2.42$ \\
\hline $\mathrm{T}-10$ & 13.41 & 1.41 & 7.06 & 5.70 & $1.92 / 2.37$ & C9 & $6.72 / 8.37$ & 5.49 & 7.43 & 5.51 & $2.08 / 2.40$ \\
\hline G-9 & 12.59 & - & 7.79 & 5.65 & $2.66 / 2.68$ & A10 & - & 7.56 & 8.28 & 6.20 & $2.65 / 2.90$ \\
\hline G-8 & 12.76 & - & 7.62 & 5.94 & $2.52 / 2.72$ & T11 & 13.37 & 1.44 & 7.16 & 5.53 & $2.00 / 2.33$ \\
\hline $\mathrm{T}-7$ & 13.93 & 1.33 & 7.27 & 6.02 & $2.02 / 2.48$ & A12 & - & 7.28 & 8.15 & 6.01 & $2.69 / 2.84$ \\
\hline $\mathrm{T}-6$ & 13.85 & 1.67 & 7.34 & 5.97 & $1.99 / 2.34$ & G13 & 12.91 & - & 7.65 & 5.78 & $2.44 / 2.62$ \\
\hline A-5 & - & n.d. & 8.29 & 6.33 & $2.47 / 2.72$ & $\mathrm{C} 14$ & $6.61 / 8.14$ & 5.33 & 7.37 & 6.10 & $2.15 / 2.16$ \\
\hline
\end{tabular}

\footnotetext{
${ }^{a}$ Not determined.
} 
$45^{\circ} \mathrm{C}$
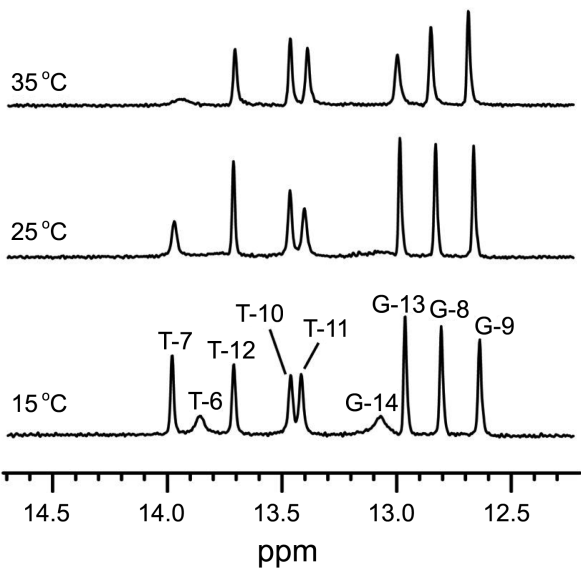

Figure 2. Temperature dependence of the imino proton resonances of the ${ }^{1} \mathrm{H}-\mathrm{NMR}$ spectra for the wt galP1 duplex. The experimental temperatures are shown on the left of spectra.

gradient triple resonance probe. 1D NMR data were processed and analyzed with the program FELIX (Accelrys) or VNMR $J$ and 2D data were processed with the program NMRPIPE and analyzed with the program Sparky. The exchange rates of the imino protons were determined as previously described. ${ }^{9}$ The hydrogen exchange rates of the imino protons were measured by water magnetization transfer experiments. ${ }^{9}$ The imino hydrogen exchange rate constants $\left(k_{\mathrm{ex}}\right)$ were determined by fitting the data to Eq. $(1):^{9}$

$$
\frac{I(t)}{I_{0}}=1-2 \frac{k_{\mathrm{ex}}}{\left(R_{1 \mathrm{w}}-R_{1 \mathrm{a}}\right)}\left(e^{-R_{1 \mathrm{a}} t}-e^{-R_{1 \mathrm{w}} t}\right)
$$

where $R_{1 \mathrm{a}}$ and $R_{1 \mathrm{w}}$ were the independently measured and are the apparent longitudinal relaxation rates of the imino proton and water, respectively, and $I_{0}$ and $I(t)$ are the peak intensities of the imino proton in the water magnetization transfer experiments at times zero and $t$, respectively. ${ }^{9}$

\section{Results and Discussion}

Two-dimensional NOESY spectra of the wt galP1 duplex in $90 \% \mathrm{H}_{2} \mathrm{O} / 10 \% \mathrm{D}_{2} \mathrm{O}$ buffer solution containing $10 \mathrm{mM}$ sodium phosphate $(\mathrm{pH} 8.0)$ and $100 \mathrm{mM} \mathrm{NaCl}$ were acquired at $5{ }^{\circ} \mathrm{C}$ with 150 and $300 \mathrm{~ms}$ mixing times. The non-exchangeable base and sugar protons were assigned according to their intra-residue and sequential NOE connectivities. The exchangeable protons were assigned by the strong G-imino to C-amino or T-imino to A-H2 NOE cross peaks in the NOESY spectra. The chemical shift of the proton resonances of the wt galP1 duplex are given in Table 1. In temperature-dependent imino proton spectra (Fig. 2), all imino proton resonances except that of the terminal A-5.T5 base pair could be observed at $15^{\circ} \mathrm{C}$. However, all imino proton resonances disappeared at $45^{\circ} \mathrm{C}$, indicating that this DNA decamer duplex is very unstable and has very low melting temperature. The T- 6 imino proton resonance was broadened at $15^{\circ} \mathrm{C}$ and then disappeared as temperature was increased up to $25^{\circ} \mathrm{C}$, like terminal G-14 imino proton, indicating instability of the T-6.A6 base pair (Fig. 2).

The exchange rate constants of the imino protons for the wt galP1 duplex were determined by water magnetization transfer method at $35^{\circ} \mathrm{C}$. Some imino protons show large differences in peak intensities as a function of delay time after water inversion (Fig. 3). For example, rapid exchanging imino protons such as T-7 and G13 show negative peaks at short delay times (40 ms in Fig. 3(a)), whereas the G-9 resonance, which is the slowest exchanging imino proton, shows still positive up to $100 \mathrm{~ms}$. The relative peak intensities of the water magnetization transfer for the imino proton resonances of the wt galP1 duplex at $35^{\circ} \mathrm{C}$ are plotted as a function of delay time in Fig. 3(b). Fig. 3(c) shows the $k_{\text {ex }}$ data of the imino protons of the wt galP1 duplex determined by fitting to Eq. (1). The central G-9 imino proton is the slowest exchanging proton $\left(k_{\mathrm{ex}}\right.$ of $6.6 \pm 0.2 \mathrm{~s}^{-1}$ ), indicating that the G-9.C9 base pair is the most stable base pair in the wt galP1 duplex. The T-6 imino proton next to the terminal base pair shows no signal and the T-7 imino proton two base-pair ( $2 \mathrm{bp}$ ) next to the terminal base pair has the largest exchange rate constant of any nonterminal base pairs except T-6.A6 $\left(k_{\text {ex }}\right.$ of $\left.164.5 \pm 9.6 \mathrm{~s}^{-1}\right)$. However, the G13 and T-12 imino protons, which are two imino protons next to the other terminal base pairs, have the $k_{\mathrm{ex}}$ values of $27.6 \pm 0.2 \mathrm{~s}^{-1}$ and $18.6 \pm 0.2 \mathrm{~s}^{-1}$, respectively, (a)

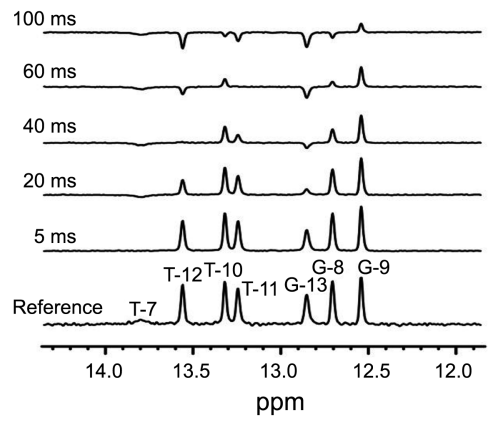

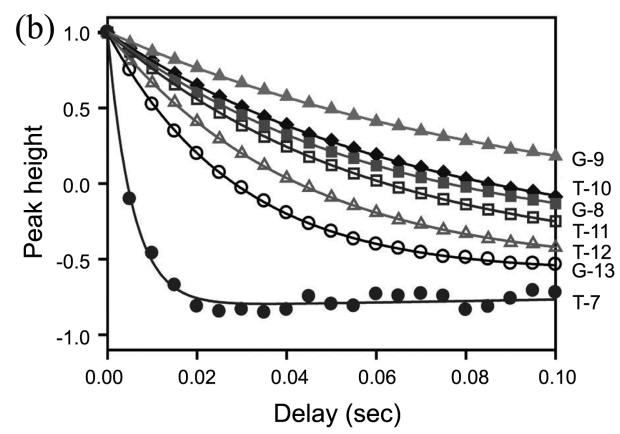

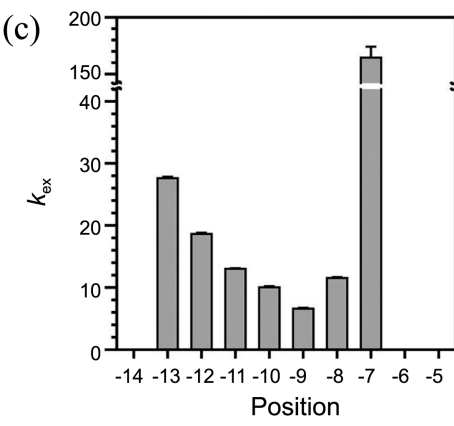

Figure 3. (a) 1D imino proton spectra of the water magnetization transfer experiments for the wt galP1duplex at $35^{\circ} \mathrm{C}$. The delay times between the selective water inversion and acquisition pulse are indicated on the left of spectra. (b) Relative peak height $\left[I(t) / I_{0}\right]$ in the water magnetization transfer spectra for the imino protons as a function of delay time. Solid lines indicate the best fitting of these data using Eq. (1). (c) The exchange rate constants of the imino protons for the wt galP1 duplex at $35^{\circ} \mathrm{C}$ and the error bars represents fitting errors. 

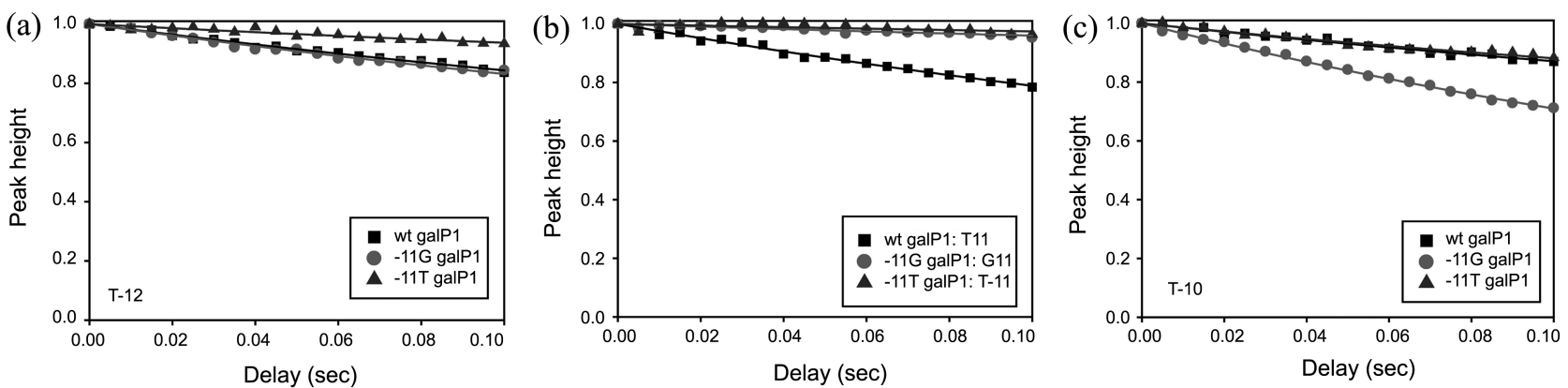

Figure 4. Relative peak height $\left[I(t) / I_{0}\right]$ in the water magnetization transfer spectra for the (A) T-12, (B) X-11, and (C) T-10 imino protons of the wt, $-11 \mathrm{G}$, and $-11 \mathrm{~T}$ galP1 duplexes as a function of delay time. Solid lines indicate the best fitting of these data using Eq. (1). (C) The exchange rate constants of the imino protons for the wt galP1 duplex at $35^{\circ} \mathrm{C}$ and the error bars represents fitting errors.

Table 2. Hydrogen exchange rate constants $\left(\mathrm{s}^{-1}\right)$ of the imino protons for the wt, $-11 \mathrm{G}$, and $-11 \mathrm{~T}$ galP1 decamer duplexes at $15^{\circ} \mathrm{C}$

\begin{tabular}{cccrr}
\hline Base pair & Imino & wt galP1 & $-11 \mathrm{G}$ galP1 & $-11 \mathrm{~T}$ galP1 \\
\hline $\mathrm{G}-14 \cdot \mathrm{C} 14$ & $\mathrm{G}-14$ & $85.3 \pm 4.1$ & $81.9 \pm 4.7$ & $120.3 \pm 8.6$ \\
$\mathrm{C}-13 \cdot \mathrm{G} 13$ & $\mathrm{G} 13$ & $1.3 \pm 0.1$ & $1.3 \pm 0.2$ & $1.2 \pm 0.3$ \\
$\mathrm{~T}-12 \cdot \mathrm{A} 12$ & $\mathrm{~T}-12$ & $0.9 \pm 0.2$ & $1.0 \pm 0.3$ & $0.4 \pm 0.2$ \\
$\mathrm{X}-11 \cdot \mathrm{Y} 11$ & $\mathrm{X}-11 / \mathrm{Y} 11$ & $1.3 \pm 0.2$ & $0.2 \pm 0.1$ & $0.2 \pm 0.1$ \\
$\mathrm{~T}-10 \cdot \mathrm{A} 10$ & $\mathrm{~T}-10$ & $0.7 \pm 0.2$ & $1.8 \pm 0.2$ & $0.7 \pm 0.2$ \\
G-9·C9 & G-9 & $0.4 \pm 0.2$ & $0.3 \pm 0.2$ & $0.3 \pm 0.2$ \\
G-8·C8 & $\mathrm{G}-8$ & $0.5 \pm 0.2$ & $0.4 \pm 0.2$ & $0.6 \pm 0.2$ \\
$\mathrm{~T}-7 \cdot \mathrm{A} 7$ & $\mathrm{~T}-7$ & $7.5 \pm 0.1$ & $9.4 \pm 0.2$ & $7.7 \pm 0.4$ \\
T-6·A6 & $\mathrm{T}-6$ & $55.1 \pm 1.3$ & $66.4 \pm 3.1$ & $61.4 \pm 2.7$ \\
\hline
\end{tabular}

indicating that this terminal region of the wt galP1 duplex is more stable than the other terminal region.

To further understand the dynamic property of the -10 galP1 promoter sequence, the $k_{\mathrm{ex}}$ measurements were performed at $15^{\circ} \mathrm{C}$ in the wt and modified galP1 duplexes. In the $-11 \mathrm{G}$ galP1 duplex, where A·T base-pair is changed to $\mathrm{G} \cdot \mathrm{C}$ at the -11 position (see Fig. 1), the peak intensity of the G-11 imino proton shows much smaller dependence on the delay time after selective water inversion compared to the wt galP1 duplex (Fig. 4(b)). This leads to a 6-fold smaller $k_{\text {ex }}$ value of the G-11 imino proton than the T11 imino proton in the wt galP1 duplex (Table 2), demonstrating that the A·T base pair is much less stable than the corresponding $\mathrm{G} \cdot \mathrm{C}$ base pair. This difference in the base-pair stability between the $\mathrm{A} \cdot \mathrm{T}$ and $\mathrm{G} \cdot \mathrm{C}$ base pairs also affects the $k_{\mathrm{ex}}$ for the T-10 imino proton of the neighboring base-pair (Fig. 4(c)). The $\mathrm{T}-10$ imino proton in the $-11 \mathrm{G}$ galP1 duplex has 2-fold larger $k_{\mathrm{ex}}$ value than that of the wt galP1 duplex (Table 2). However, there is no significant difference in the $k_{\text {ex }}$ value between two duplexes for the T-12.A12 base pair (Fig. 4(a)). These results indicate that the change from A.T to $\mathrm{G} \cdot \mathrm{C}$ base pair at the -11 position in the galP1 promoter sequence leads to stabilization of this base pair but slight destabilization of the neighboring base pair on only one side of the substitution.

Hydrogen exchange experiments were also performed at $15^{\circ} \mathrm{C}$ for the $-11 \mathrm{~T}$ galP1 duplex, where $\mathrm{A} \cdot \mathrm{T}$ base pair is inverted to $\mathrm{T} \cdot \mathrm{A}$ base pair at the -11 position (see Fig. 1). Surprisingly, the peak intensity of the T-11 imino proton showed a weaker dependence on the delay time compared to the wt galP1 duplex (Fig. 4(b)), leading to a 6-fold smaller $k_{\text {ex }}$ value of the T-11 imino proton than the T11 imino proton in the wt galP1 duplex (Table 2). In addition, The T-12 imino proton in the -11T galP1 duplex has 2-fold smaller $k_{\mathrm{ex}}$ value than that of the wt galP1 duplex (Fig. 4(a) and Table 2). These results demonstrate that the base pair inversion at the -11 position also leads to stabilization of this base pair as well as the neighboring base pair on only one side of the substitution.

In summary, we determined the $k_{\mathrm{ex}}$ values of the imino protons in the wild-type galP1 promoter as well as the modified promoters using NMR spectroscopy. The substitution of the A-11-T11 base pair of the galP1 promoter leads to greater stabilization of this base pair as well as and the neighboring base pairs. This stabilization of the base pair in the promoter sequence might strongly interfere with the open complex formation during transcription initiation. Thus, this hydrogen exchange study can explain why the conversed $\mathrm{A} \cdot \mathrm{T}$ base pair at the -11 position of the promoter in $E$. coli transcription is very sensitive to substitution.

Acknowledgments. We thank Dr. Jongchul Bang and Prof. Byong-Seok Choi (KAIST) for assistance with the NMR experiments. This Work was supported by the National Research Foundation of Korea Grants (2010-0014199 and NRF-C1ABA001-2010-0020480) funded by the Korean Government (MEST).

\section{References}

1. Minakhin, L.; Severinov, K. J. Biol. Chem. 2003, 278, 29710.

2. Gross, C. A.; Chan, C.; Dombroski, A.; Gruber, T.; Sharp, M.; Tupy, J.; Young, B. Cold Spring Harb. Symp. Quant. Biol. 1998, $63,141$.

3. McClure, W. R. Annu. Rev. Biochem. 1985, 54, 171.

4. deHaseth, P. L.; Helmann, J. D. Mol. Microbiol. 1995, 16, 817.

5. Severinov, K.; Darst, S. A. Proc. Natl. Acad. Sci. USA 1997, 94 , 13481.

6. Grimes, E.; Busby, S.; Minchin, S. Nucleic Acids Res. 1991, 19, 6113.

7. Burns, H.; Minchin, S. Nucleic Acids Res. 1994, 22, 3840.

8. Lee, H. J.; Lim, H. M.; Adhya, S. J. Biol. Chem. 2004, 279, 16899.

9. Lee, J.-H.; Pardi, A. Nucleic Acids Res. 2007, 35, 2965. 